\title{
Конструктор-пазл «инженерные сказки»
}

Мозгачева К.А., Кузнецова К.А., учащиеся, МОУ Информационно-технологический лицей №24, 2. Нерюнгри

\section{Научные руководители: учитель робототехники Дёминов С.И., педагог дополнительного образования Миколайчук В.А., учитель информатики Чистякова Р.Н.}

Конструктор - это набор стандартных деталей, из которых можно собрать множество разных моделей. Готовые части исключают время, необходимое для изготовления специфичных деталей на заказ, а также не требуют специальной подготовки для создания сложных систем. Конструкторы используются для построения временных механизмов, а также в качестве детских игрушек.

Актуальность: в настоящее время практически отсутствуют конструкторы отечественного производства, а конструкторы заменители иностранного производства, к сожалению, не всегда соответствуют современным стандартам качества и безопасности.

Цель работы: создание конструктора для детей от 3 лет.

Задачи:

4. Создать 3D модели деталей конструктора;

5. Изготовить детали конструктора используя 3D печать;

6. Подготовить эскизы будущих проектов;

7. Создать приложение для работы с конструктором.

Предмет исследования: конструктор для детей дошкольного возраста.

Объект исследования: качество деталей конструктора.

Новизна исследования: использование на занятиях и дома конструктора позволяет в игровой форме получать знания школьной программы.

Практическая значимость: данный конструктор имеет преимущества в виде низкой цены и при этом высокого качества исполнения деталей.

1. Этап Создание 3D модели деталей конструктора

Создаем в программе Kompas-3Dмодель будущих деталей конструктора. Детали конструктора, будут отличаться размером, используя детали разного размера, ребенок сможет при работе с конструктором создавать собственные уникальные конструкции. Сохраняем проект каждой детали в формате STL (Рисунок 1): 


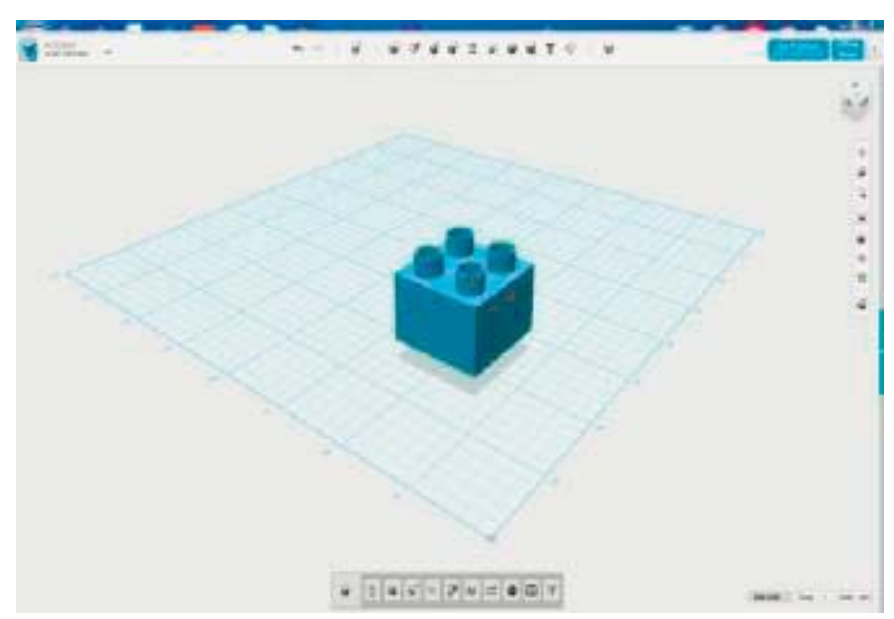

Рис. 1. Деталь в формате STL

STL (от англ. stereolithography) - формат файла, широко используемый для хранения трёхмерных моделей объектов для использования в технологиях быстрого прототипирования методом стереолитографии.

\section{2. Этап. Печать деталей на 3D принтере}

Подготавливаем проект к печати, использую программу для работы с 3Dпринтером. При печати используем пластики различных цветов (красный, синий, зеленый). Различный цвет деталей конструктора позволяет лучше ориентироваться ребенку при работе с конструктором (рис. 2):

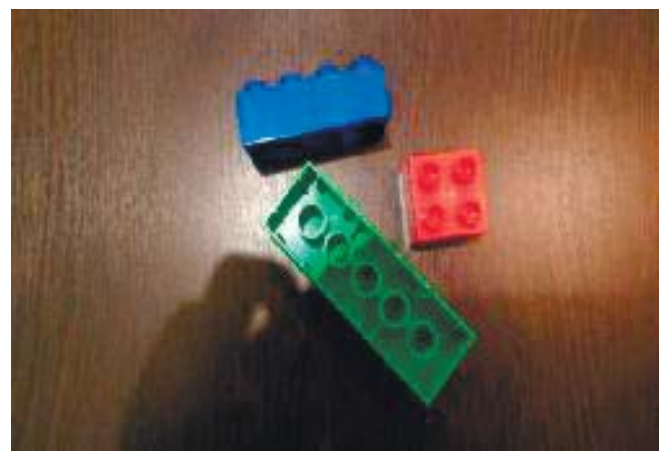

Рис. 2. Детали конструктора разного цвета

\section{3 Этап. Разработка элементов конструктора}

С помощью графического планшета подготавливаем черно-белые наброски будущих фонов для конструктора (рис. 3):

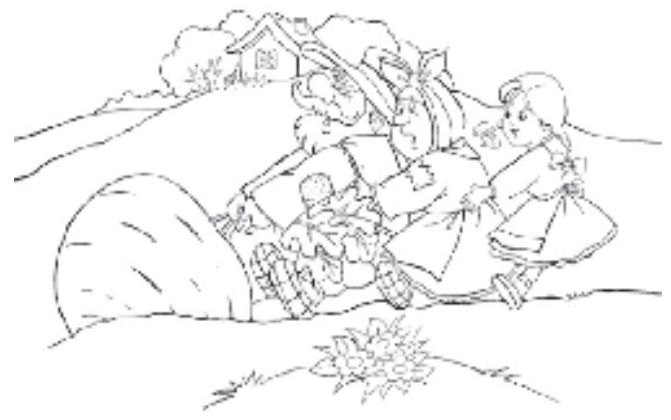

Рис. 3. Черно-белый набросок рисунка 
Обводим линии и детали эскизов, а также наносим краски на готовые изображения. Черно-белые варианты используем в последующем в качестве раскрасок.

Изготавливаем, по две копии рисунка на самоклеящейся бумаге, один из которых наносим на плотный картон, а второй наносим на собранный из распечатанных на 3D принтере деталей конструктор (рис. 4):

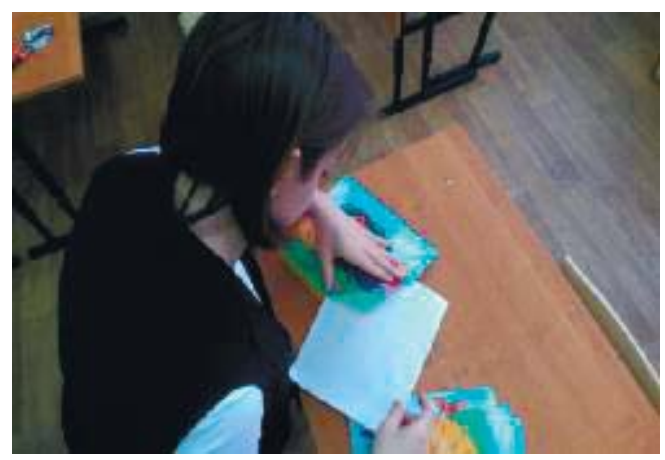

Рис. 4. Наносим наклейку

Разрезаем по контуру деталей наклейку, создавая своего рода пазл, будущей картинки собранной из деталей конструктора. Разбираем конструктор на отдельные детали.

\section{4 этап. Приложение для работы с конструктором}

Программа для работы с конструктором представляет собой приложение, выполненное в MS Power Point (интерактивная презентация) (Рисунок 5).

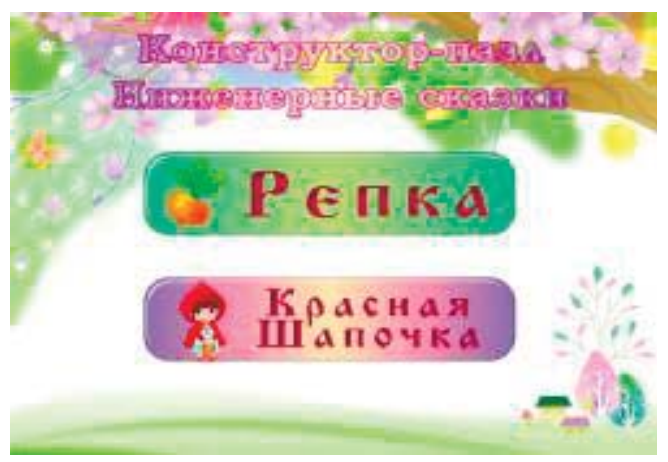

Рис. 5. Оболочка программы

Для работы с программой:

1. Не требуется устанавливать дополнительные программные продукты;

2. Не требуются навыки программиста;

3. Достаточно скопировать папку с файлами и запустить программу.

$\mathrm{C}$ помощью приложения ребенок может не только посмотреть элементы сборки данного конструктора, но и в любой момент прослушать или прочитать любое из предложенных произведений известных авторов или русских народных сказок (рис. 6): 


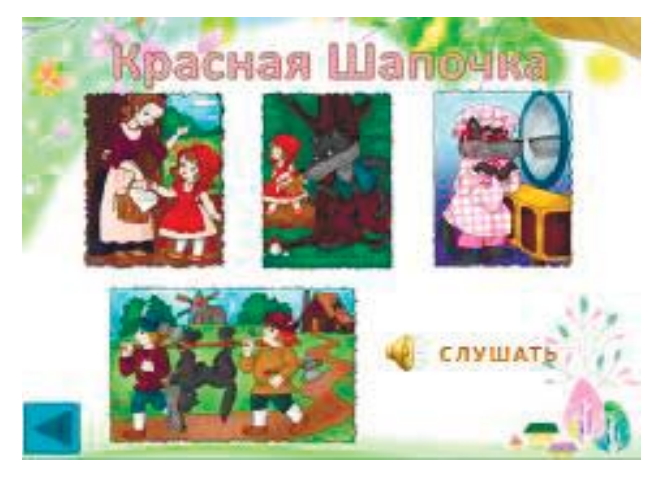

Рис. 6. Функция прослушивания сказки

\section{Заключение}

В ходе исследовательской работы были изучены теоретические основы и история развития наборов для конструирования. Было проведено исследование иностранных аналогов конструкторов с целью выявления достоинств и недостатков каждого из представленных на рынке наборов, а также разработан прототип конструктора пазла отечественного производства, не уступающего по качеству и безопасности, иностранным аналогам, но на порядок дешевле.

\section{Список литературы:}

1. Ишмакова М.С. Конструирование в дошкольном образовании в условиях введения ФГОС. Учебное пособие, Маска, М., 2013.

2. Комарова Т., Савенков А.Дошкольная педагогика. Коллективное творчество детей. Учебное пособие для СПО, ЮРАЙТ, М., 2009.

3. https://ru.wikipedia.org/wiki

4. http://kompas.ru

5. http://www.prorobot.ru

\section{Применение математики в электротехнике}

Нозирзода Ш.С., студент, Юргинский технологический институт (филиал) Томского политехнического университета, 2. Hрга E-mail: shoni 1997@mail.ru

Научный руководитель: к.n.н., доцент Гиль Л.Б.

Аннотация: В данной работе рассмотрен вопрос межпредметных связей электротехники и математики на примере задачи из электротехники, решаемой методами линейной алгебры. Также показано использование других разделов математики для решения практических задач по электротехнике.

Ключевые слова: математика, электротехника, задачи, применение.

Анализ научной, методической, научно-технической литературы, опрос инженерно-технических работников показал, что вопрос о роли и месте математики в 